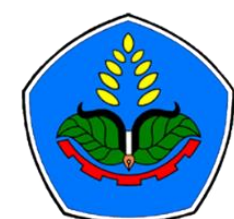

AGROPROSS

National Conference

Proceedings of Agriculture
Proceedings:

Peran Teaching Factory di Perguruan Tinggi Vokasi Dalam Mendukung Ketahanan Pangan Pada Era New Normal

Tempat : Politeknik Negeri Jember

Tanggal : 8-9 Juli 2020

Publisher :

Agropross, National Conference Proceedings of Agriculture

ISBN : 978-623-94036-6-9

DOI : 10.25047 /agropross.2020.45

\title{
Pengaruh Dosis Mikoriza (Vam) Terhadap Pertumbuhan Awal Bibit Dua Varietas Tebu (Saccharum Officinarum L.) Varietas Sp 80-1816 Dan Ps 882 Pada Tahap Aklimatisasi
}

\author{
Author(s): Ichlasul Amal ${ }^{1) *}$; M. Bintoro ${ }^{1)}$, dan Alfarina Kardiana Sari ${ }^{2)}$ \\ (1) Program Studi Teknik Produksi Benih, Jurusan Produksi Pertanian, Politeknik Negeri Jember \\ (2) Peneliti Pusat Penelitian Gula Jengkol PT Perkebunan Nusantara X Kediri Jawa Timur. \\ * Corresponding author: ichlasul56@gmail.com
}

\begin{abstract}
One of the ways to increase sugar production is by increasing the quality of sugar cane seeds. The quality of sugar cane seeds before being moved to the field can be improved by adding microorganisms in the soil, namely mycorrhizae at the acclimatization stage. The purpose of this study was to determine the effect of VAM mycorrhizal doses on the initial growth of SP 80-1816 and PS 882 sugar cane seedlings at the acclimatization stage. This research was designed using a factorial randomized block design with 2 factors. The first factor is mycorrhizal dose consisting of 4 levels, namely without mycorrhizal treatment (M0), 5 grams of mycorrhizal / polybag (M1), 8 grams of mycorrhizal / polybag (M2), and 11 grams of mycorrhizal / polybag (M3). The second factor is sugar cane variety which consists of 2 levels, namely SP 80-1816 (V1) and PS 882 (V2). Each treatment combination was repeated 3 times. The results showed that the interaction between mycorrhizal doses and varieties showed no significantly in all parameters. While the single factor, mycorrhizal dose showed a very significantly in the number of tillers, but not significantly different in the parameters of plant height, number of leaves, stem diameter, wet weight, and dry weight of sugarcane seeds. The most number of tillers was shown by sugarcane seedlings that were given as much as 8 grams / polybag, which was 6.60. The dose of mycorrhizal also showed significantly in the length of root with the result that the seeds given mycorrhiza had better than those not given. The variety factor is significantly only in the plant height parameter at the age of 4 weeks after planting where Variety SP 80-1816 (V1) has the best response compared to variety PS 882 (V2).
\end{abstract}

\section{Kata Kunci: \\ Tahap \\ aklimatisasi;}

Bibit tebu;

Mikoriza VAM

\section{Keywords: \\ Acclimatization stage;}

\section{Sugarcane} seedling;

VAM mycorrhyzal

\begin{abstract}
ABSTRAK
Salah satu cara untuk meningkatkan produksi gula adalah dengan meningkatkan kualitas bibit tebu. Kualitas bibit tebu sebelum dipindahkan ke lapangan dapat ditingkatkan dengan menambahkan mikroorganisme dalam tanah, yaitu mikoriza pada tahap aklimatisasi. Tujuan dari penelitian ini adalah untuk mengetahui pengaruh dosis mikoriza VAM terhadap pertumbuhan awal SP 80-1816 dan bibit tebu PS 882 pada tahap aklimatisasi. Penelitian ini dirancang menggunakan rancangan acak kelompok faktorial dengan 2 faktor. Faktor pertama adalah dosis mikoriza yang terdiri dari 4 taraf, yaitu tanpa perlakuan mikoriza (M0), 5 gram mikoriza / polibag (M1), 8 gram mikoriza / polibag (M2), dan 11 gram mikoriza / polibag (M3). Faktor kedua adalah varietas tebu yang terdiri dari 2 taraf, yaitu SP 80-1816 (V1) dan PS 882 (V2). Setiap kombinasi perlakuan diulang 3 kali. Hasil penelitian menunjukkan bahwa interaksi antara dosis mikoriza dan varietas tidak menunjukkan signifikan pada semua parameter. Sedangkan faktor tunggal, dosis mikoriza menunjukkan jumlah anakan yang sangat signifikan, tetapi tidak berbeda nyata pada parameter tinggi tanaman, jumlah daun, diameter batang, berat basah, dan berat kering bibit tebu. Jumlah anakan terbanyak ditunjukkan oleh bibit tebu yang diberikan sebanyak 8 gram / polybag, yaitu 6,60. Dosis mikoriza juga menunjukkan secara signifikan panjang akar dengan hasil bahwa bibit yang diberi mikoriza lebih baik daripada yang tidak diberikan. Varietas faktor secara signifikan hanya dalam parameter tinggi tanaman pada umur 4 minggu setelah tanam dengan Varietas SP 80-1816 (V1) memiliki respon terbaik dibandingkan dengan varietas PS 882 (V2).
\end{abstract}




\section{PENDAHULUAN}

Tebu (Saccharum officinarum L.) merupakan salah satu komoditas perkebunan yang memiliki peranan penting bagi ekonomi Indonesia. Tebu dimanfaatkan untuk dijadikan sebagai bahan baku gula. Berdasarkan data Kementerian Perindustrian Republik Indonesia produksi gula berbasis tebu pada tahun 2018 sebesar 2, 17 juta ton. Sedangkan kebutuhan gula nasional mencapai 6,6 juta ton. Berdasarkan data tersebut diperlukan peningkatan kualitas baik secara on farm ataupun pembangunan fasilitas penunjang pengolahan tebu seperti pembangunan pabrik gula dengan kapasitas produksi yang berkapasitas tinggi. Peningkatan kualitas secara on farm merupakan salah satu cara yang dapat diterapkan untuk meningkatkan produktivitas tebu yaitu dengan perbanyakan tebu secara kultur jaringan. Salah satu tahapan yang dapat menentukan keberhasilan dalam kultur jaringan yaitu tahap aklimatisasi. Aklimatiasi merupakan proses adaptasi tanaman hasil pada kondisi lingkungan baru sebelum ditanam dilapang. Tanaman hasil kultur jaringan membutuhkan proses adaptasi terhadap lingkungan karena kondisi lingkungan pada botol kultur berbeda dengan kondisi dilapang yaitu tidak adanya lapisan lilin pada tanaman dan stomata daun tidak berfungsi. Oleh karena itu perlu diberi perlakuan pada pembibitan tebu hasil kultur jaringan dengan pemberian mikoriza. Mikoriza merupakan cendawan dalam tanah yang dapat bersimbiosis dengan akar tanaman inang sehingga dapat menguntungkan untuk pertumbuhan dan perkembangan tanaman. Peran mikoriza untuk tanaman begitu luas sehingga pada penelitian ini perlu diberi perlakuan mikoriza.

\section{BAHAN DAN METODE}

Penelitian ini dilaksanakan pada bulan Agustus sampai November 2019. Penelitian ini dilaksanakan di Pusat Penelitian Gula Jengkol PT Perkebunan Nusantara X Kediri Jawa Timur.

Alat yang digunakan yaitu gembor, alat tulis kantor, meteran kain, timba plastik, gunting, timbangan analitik, oven dan jangka sorong. Bahan yang digunakan yaitu bibit tebu varietas SP 80-1816 dan PS 882 hasil aklimatisasi yang berumur 2 bulan, mikoriza VAM dengan merek dagang biosakarofert, polibag, media tanah dan kertas label.

Penelitian ini dilaksanakan dengan menggunakan Rancangan Acak Kelompok (RAK) secara faktorial, yang terdiri dari 2 faktor, faktor pertama terdiri 4 level yaitu dosis mikoriza $\mathrm{M} 0=$ Tidak diberi Mikoriza (kontrol), $\mathrm{M} 1=5$ gram $/$ polibag, $\mathrm{M} 2=8$ gram / polibag, M3 = 11 gram / polibag. Sedangkan faktor kedua terdiri 2 level yaitu varietas tebu V1 = SP 80-1816 dan $\mathrm{V} 2=\mathrm{PS}$ 882. Terdapat 8 kombinasi perlakuan dan masing-masing perlakuan diulang sebanyak 3 kali sehingga diperoleh 24 unit perlakuan.

Data hasil penelitian diolah secara statistic menggunakan Analysis Of Variance (ANOVA). Apabila hasil menunjukkan pengaruh yang nyata dan sangat nyata maka akan diuji lanjut dengan Uji Beda Nyata Terkecil (BNT) taraf 5\% dan $1 \%$.

Prosedur penelitian meliputi persiapan alat dan bahan, persiapan media tanam, pemberian perlakuan mikoriza pada media tanam, pemotongan daun dan akar bibit tebu, transplanting bibit tebu, penyiraman bibit tebu dan pemeliharaan tanaman. Parameter yang diamati yaitu tinggi tanaman $(\mathrm{cm})$, Jumlah daun (helai), Berat Basah Tanaman (gram), Berat Kering Tanaman (gram), jumlah anakan, Panjang akar $(\mathrm{cm})$, dan diameter batang $(\mathrm{cm})$. 
Tabel 1. Rekapitulasi Hasil Sidik Ragam Seluruh Parameter

\begin{tabular}{|c|c|c|c|c|}
\hline \multirow{2}{*}{ No } & \multirow{2}{*}{ Parameter Pengamatan } & \multicolumn{3}{|c|}{ Perlakuan } \\
\hline & & $\mathbf{M}$ & $\mathbf{V}$ & M X V \\
\hline 1 & Tinggi Tanaman 4 MST & ns & $* *$ & $\mathrm{~ns}$ \\
\hline 2 & Tinggi Tanaman 8 MST & ns & ns & ns \\
\hline 3 & Tinggi Tanaman $12 \mathrm{MST}$ & ns & ns & $\mathrm{ns}$ \\
\hline 4 & Jumlah Daun 4 MST & ns & ns & ns \\
\hline 5 & Jumlah Daun 8 MST & ns & ns & $\mathrm{ns}$ \\
\hline 6 & Jumlah Daun 12 MST & ns & ns & $\mathrm{ns}$ \\
\hline 7 & Diameter Batang & ns & ns & $\mathrm{ns}$ \\
\hline 8 & Jumlah Anakan & $* *$ & ns & $\mathrm{ns}$ \\
\hline 9 & Berat Basah Tanaman & ns & ns & $\mathrm{ns}$ \\
\hline 10 & Berat Kering Tanaman & ns & ns & $\mathrm{ns}$ \\
\hline 11 & Panjang Akar & $*$ & ns & ns \\
\hline
\end{tabular}

$$
\begin{aligned}
\text { Keterangan } * & =\text { Berbeda nyata } \\
* * & =\text { Berbeda sangat nyata } \\
\mathrm{ns} & =\text { Berbeda tidak nyata } \\
\mathrm{M} & =\text { Mikoriza } \\
\mathrm{V} & =\text { Varietas }
\end{aligned}
$$

\section{HASIL DAN PEMBAHASAN}

Interaksi antara pemberian mikoriza dengan varietas tanaman tebu memberikan pengaruh yang tidak nyata terhadap semua parameter pengamatan. Namun masingmasing faktor, baik faktor varietas maupun pemberian mikoriza memberikan pengaruh yang nyata sampai sangat nyata terhadap pertumbuhan benih tebu.

Perlakuan pemberian mikoriza memberikan pengaruh yang tidak nyata terhadap tinggi tanaman 4 MST, 8 MST, 12 MST, jumlah daun, diameter batang, berat basah tanaman dan berat kering tanaman. Namun memberikan pengaruh yang sangat nyata terhadap jumlah anakan dan nyata terhadap panjang akar.

Perlakuan varietas tebu memberikan pengaruh yang sangat nyata terhadap tinggi tanaman umur 4 MST dan tidak nyata umur 8 dan 12 MST. Demikian juga terhadap jumlah daun, diameter batang, jumlah anakan, berat basah, berat kering dan panjang akar.

\section{Tinggi Tanaman}

Untuk mengetahui pertumbuhan tanaman fase vegetatif, diukur tinggi tanaman. Parameter tinggi tanaman diamati pada umur 4 MST, 8 MST dan 12 MST. Pengaruh Varietas (V) terhadap tinggi tanaman $(\mathrm{cm})$ dapat dilihat pada Tabel 2.

Tabel 2. Pengaruh Varietas (V) Terhadap Tinggi Tanaman (cm)

\begin{tabular}{llll}
\hline Varietas & 4 MST & 8 MST & 12 MST \\
\hline V1(SP & $147,26 \mathrm{~b}$ & $159,9 \mathrm{a}$ & $208,37 \mathrm{a}$ \\
80-1816) & & & \\
\hline V2 (PS & $123,67 \mathrm{a}$ & $153,43 \mathrm{a}$ & $197,43 \mathrm{a}$ \\
$882)$ & & & \\
\hline
\end{tabular}

Keterangan: angka yang diikuti dengan huruf yang sama menunjukkan berbeda tidak nyata pada uji BNT 1\%.

Varietas tebu memberikan pengaruh yang sangat nyata terhadap tinggi tanaman pada umur 4 MST. Varietas tebu SP 801816 (V1) mempunyai respon yang lebih baik dibandingkan varietas PS 882 dalam hal tinggi tanaman pada umur 4 MST, yaitu $147,26 \mathrm{~cm}$. Perbedaan respon pertumbuhan antara varietas SP 80-1816 dengan varietas 
PS 882 tidak terlepas dari sifat genetik varietas. Menurut Putra, dkk (2016) perbedaan susunan genetik merupakan salah satu faktor penyebab keragaman penampilan tanaman. sifat genetik yang diekspresikan pada suatu fase pertumbuhan yang berbeda dapat diekspresikan pada berbagai sifat tanaman yang mencakup bentuk dan fungsi tanaman yang menghasilkan keragaman pertumbuhan tanaman. Varietas tebu pada umur 8 dan 12 MST memberikan respon yang sama terhadap tinggi tanaman. Hal tersebut menunjukkan bahwa respon pertumbuhan tinggi tanaman varietas tebu terlihat pada fase awal ketika tanaman berumur 4 MST. Pada jangka umur tersebut terjadi pertumbuhan tanaman secara aktif dimana penyerapan unsur hara yang dilakukan oleh tanaman semakin aktif sehingga respon pertumbuhan varietas tebu dapat terlihat.

Pemberian mikoriza pada tanaman tebu memberikan pengaruh yang tidak nyata pada parameter tinggi tanaman. Hal tersebut menunjukkan bahwa kehadiran mikoriza sampai umur 12 minggu setelah tanam memberikan respon yang sama karena keberadaan mikoriza dalam tanah meningkatkan kemampuan tanaman dalam proses penyerapan air dan unsur hara terutama unsur P saat umur 4 MST, 8 MST dan 12 MST. Menurut Adelman dan Morton (1986) infeksi cendawan MVA meningkatkan pertumbuhan tanaman dan meningkatkan kemampuan untuk memanfaatkan unsur hara terutama unsur $\mathrm{P}, \mathrm{Ca}, \mathrm{N}, \mathrm{Cu}, \mathrm{K}, \mathrm{Mn}$ dan $\mathrm{Mg}$.

\section{Jumlah Daun}

Daun merupakan salah satu organ penting bagi tanaman. daun berfungsi sebagai tempat fotosintesis yang kemudian hasil fotosintesis tersebut ditransportasikan ke seluruh bagian tanaman untuk pertumbuhan dan perkembangan. Pengaruh masing-masing faktor, baik pemberian mikoriza maupun varietas tebu memberikan pengaruh yang tidak nyata terhadap jumlah daun. Demikian juga interaksi dua faktor tersebut juga memberikan pengaruh yang tidak nyata. Kehadiran mikoriza dan varietas tebu sampai umur 12 Minggu Setelah Tanam memberikan respon yang sama. Jumlah daun menjadi indicator ketersediaan unsur hara dalam tanah. Meningkatnya jumlah daun tidak terlepas dari penyerapan unsur hara. Menurut Mashud (2013) Unsur hara $\mathrm{N}$, P, dan $\mathrm{K}$ merupakan unsur hara yang paling banyak diserap tanaman, sehingga apabila terjadi kekurangan unsur tersebut akan menyebabkan menurunnya aktivitas pertumbuhan dan produksi tanaman. Selain itu meningkatnya jumlah daun disebabkan adanya aktivitas pertumbuhan dan perkembangan tanaman. Menurut Anindita (2017) meningkatnya jumlah daun tidak terlepas dari adanya aktifitas pemanjangan sel yang merangsang terbentuknya daun sebagai organ fotosintesis. Daun secara umum dipandang sebagai organ produsen fotosintat utama.

\section{Jumlah anakan}

Anakan pada tanaman tebu muncul diawali berkecambahnya tunas-tunas muda yang tumbuh disekitar batang utama tanaman tebu. Pertumbuhan anakan tebu merupakan proses perkecambahan dan tumbuhnya mata-mata pada batang tebu dibawah tanah yang kemudian menjadi tanaman tebu baru. Pertumbuhan anakan ini memasuki fase pertunasan, dimana fase ini sangat penting karena dengan jumlah anakan yang tumbuh banyak dapat merefleksikan produktivitas tanaman tebu (Indika,2018). Tunas yang tumbuh pada tebu dapat menjadi batang tebu yang baru. Pengaruh Perlakuan Mikoriza (M) terhadap jumlah anakan dapat dilihat pada Tabel 3. 
Tabel 3. Pengaruh Perlakuan Mikoriza (M) terhadap Jumlah Anakan

\begin{tabular}{lc}
\hline Mikoriza & Jumlah Anakan \\
\hline M2 ( 8 gram) & $6,60 \mathrm{c}$ \\
\hline M3 ( 11 gram) & $6.22 \mathrm{~b}$ \\
\hline M1 ( 5 gram) & $6.13 \mathrm{~b}$ \\
\hline M0 ( 0 gram) & $4,98 \mathrm{a}$ \\
\hline
\end{tabular}

Keterangan: angka yang diikuti dengan huruf yang sama menunjukkan berpengaruh tidak nyata pada uji BNT 1\%.

Pemberian mikoriza pada tanaman tebu dapat meningkatkan pertumbuhan jumlah anakan dibandingkan dengan tanaman tebu dengan tanpa mikoriza. Pemberian mikoriza dengan dosis 8 gram pada tanaman tebu menghasilkan jumlah anakan paling tinggi dibandingkan dengan dosis lainnya, yaitu 6,60 batang. Pemberian mikoriza dapat meningkatkan jumlah anakan tanaman tebu. Pemberian mikoriza selain dapat membantu penyerapan unsur hara juga dapat menghasilkan hormon seperti auksin, sitokinin, dan giberelin yang berguna bagi pertumbuhan dan perkembangan tanaman. Menurut Talanca (2010) tanaman yang terinfeksi cendawan MVA memperlihatkan pertumbuhan tanaman yang baik bila dibandingkan dengan tanaman yang tidak terinfeksi mikoriza, karena MVA juga menghasilkan hormon seperti auksin, sitokinin, dan giberelin.

Salah satu peranan mikoriza dalam tanah yaitu membantu proses penyerapan unsur hara dalam tanah terutama unsur P. Unsur $\mathrm{P}$ sangat berguna bagi proses pertumbuhan anakan tebu. unsur $\mathrm{P}$ dibutuhkan tanaman dalam pembentukan anakan sehingga anakan tebu dapat tumbuh dengan baik. Menurut yulianingtyas, dkk (2015) menyatakan unsur P yang dapat meningkatkan ATP sangat dibutuhkan tanaman dalam pembentukan anakan, sehingga pertumbuhan dan jumlah anakan tebu dapat tumbuh dengan optimal.

\section{Panjang akar}

Tanaman tebu memiliki tipe perakaran serabut. Struktur akar pada tanaman tebu terbagi menjadi dua, yaitu akar primer dan akar sekunder. Pengaruh perlakuan mikoriza terhadap panjang akar dapat dilihat pada Tabel 4.

Tabel 4. Pengaruh Perlakuan Mikoriza (M) Terhadap Panjang Akar (cm).

\begin{tabular}{lr}
\hline Mikoriza & Panjang Akar \\
\hline M3 ( 11 gram) & $18,30 \mathrm{~b}$ \\
\hline M2 ( 8 gram) & $18,10 \mathrm{~b}$ \\
\hline M1 ( 5 gram) & $17,44 \mathrm{~b}$ \\
\hline M0 ( 0 gram) & $13,61 \mathrm{a}$ \\
\hline
\end{tabular}

Keterangan: angka yang diikuti dengan huruf yang sama menunjukkan berpengaruh tidak nyata pada uji BNT $1 \%$.

Pemberian mikoriza pada tanaman tebu memberikan pengaruh yang nyata pada parameter panjang akar. Pemberian mikoriza pada tanaman tebu dapat meningkatkan pertumbuhan panjang akar dibandingkan tanaman tebu dengan tanpa diberi mikoriza. Pemberian Mikoriza dengan dosis 11 gram per tanaman, memberikan pengaruh yang paling baik dibadingkan dengan 2 dosis lainnya walaupun tidak menunjukkan perbedaan yang nyata. Namun, secara umum tanaman tebu yang diberi mikoriza memberikan pengaruh yang lebih baik dibandingkan dengan yang tidak diberi mikoriza.

Pertumbuhan dan perkembangan perakaran yang baik tidak terlepas dari peranan mikoriza. Mikoriza yang telah menginfeksi perakaran tanaman menyebabkan akar tanaman mengalami eksplorasi penyerapan unsur hara dalam tanah cukup besar sehingga penyerapan unsur hara dalam tanah optimal. Menurut Talanca (2015) menyatakan akar tanaman yang terinfeksi dengan cendawan MVA dapat mengeksplorasi volume tanah cukup besar sehingga penyerapan akar tanaman terhadap unsur fosfor lebih besar, yang menyebabkan tanaman dapat tumbuh dengan baik. 
Kondisi perakaran yang baik juga dapat berdampak pada proses penyerapan unsur hara dalam tanah. Sistem perakaran yang baik akan memudahkan penyerapan unsur hara dalam tanah. Menurut wardhika, dkk (2015) kondisi perakaran yang lebih baik tentunya menyebabkan unsur hara yang tersedia dalam tanah mudah diserap oleh tanaman dengan bantuan MVA.

\section{Berat Basah Tanaman (gram)}

Berat Basah Tanaman dapat dijadikan tolok ukur pertumbuhan tanaman. semakin berat suatu tanaman maka semakin bagus pertumbuhannya berkaitan dengan proses penyerapan hara yang dilakukan oleh tanaman.

Pengaruh masing-masing faktor, baik pemberian mikoriza maupun varietas tebu memberikan pengaruh yang tidak nyata terhadap berat basah tanaman. Demikian juga interaksi dua faktor tersebut juga memberikan pengaruh yang tidak nyata. Hal tersebut menunjukkan bahwa kehadiran mikoriza dan varietas tebu memberikan respon yang sama terhadap berat basah tanaman. Respon yang sama disebabkan adanya infeksi mikoriza dapat meningkatkan kemampuan tanaman dalam menyerap air dan unsur hara dalam tanah sehingga mencukupi kebutuhan nutrisi tanaman dan meningkatkan pertumbuhan. Menurut Ismayanti, dkk (2013) infeksi mikoriza akan meningkatkan luas permukaan penyerapan unsur hara dan air sehingga mencukupi kebutuhan nutrisi tanaman dan meningkatkan pertumbuhan.

\section{Berat Kering Tanaman (gram)}

Berat Kering Tanaman merupakan akumulasi senyawa organik yang berhasil disintesis oleh tanaman ke organ-organ lainnya. Pengaruh masing-masing faktor, baik pemberian mikoriza maupun varietas tebu memberikan pengaruh yang tidak nyata terhadap berat kering tanaman. Demikian juga interaksi dua faktor tersebut juga memberikan pengaruh yang tidak nyata. Hal tersebut menunjukkan bahwa kehadiran mikoriza dan varietas tebu memberikan respon yang sama terhadap berat kering tanaman. Respon yang sama diduga adanya pengaruh hara yang diserap oleh perakaran tanaman. Setiap unsur hara yang diserap memiliki fungsi dan peran yang berbeda bagi tanaman. Menurut Bailey (1986) unsur P akan mempengaruhi berat kering akar tanaman. Unsur $\mathrm{N}$ dibutuhkan oleh tanaman sepanjang pertumbuhannya sehingga jumlah yang diambil berhubungan langsung dengan produksi berat keringnya. Sementara unsur $\mathrm{K}$, $\mathrm{Ca}$, dan $\mathrm{Mg}$ tersedia dapat meningkatkan proses fotosintesis yang berlangsung pada tanaman sehingga dapat tumbuh dengan normal serta diikuti oleh peningkatan berat kering tanaman.

\section{Diameter Batang}

Pengamatan diameter batang dilakukan pada akhir penelitian. Besar kecilnya diameter batang mempengaruhi bobot akhir tebu. Tebu yang memiliki diameter batang yang besar memiliki berat yang besar. Pengaruh masing-masing faktor, baik pemberian mikoriza maupun varietas tebu memberikan pengaruh yang tidak nyata terhadap diameter batang tanaman. Demikian juga interaksi dua faktor tersebut juga memberikan pengaruh yang tidak nyata. Waktu pengamatan yang dilakukan kurang tepat sehingga menyebabkan pertumbuhan batang masih kecil sehingga varietas tebu yang diberi mikoriza dengan tanpa diberi mikoriza memberikan respon yang sama. Menurut Disbun jatim (2008) dalam Putra (2016) mengatakan fase pertumbuhan pemanjangan dan pembesaran batang terjadi pada umur tebu tebu antara 3-9 bulan, hal ini terkait dengan perubahan fisik tanaman yang terjadi secara cepat dan menghasilkan biomassa setiap periode waktu yang sangat cepat. 


\section{KESIMPULAN}

Berdasarkan uraian pembahasan dapat disimpulkan bahwa Dosis mikoriza menunjukkan pengaruh yang sangat nyata terhadap parameter jumlah anakan, tetapi tidak berbeda nyata pada parameter tinggi tanaman, jumlah daun, diameter batang, berat basah, dan berat kering tanaman tebu. Jumlah anakan terbanyak ditunjukkan oleh bibit tebu yang diberi mikoriza sebanyak 8 gram / polybag yaitu 6,60 batang.

Dosis mikoriza juga menunjukkan secara perbedaan yang nyata terhadap panjang akar dengan hasil bahwa benih tebu yang diberi mikoriza lebih baik daripada yang tidak diberi mikoriza dengan nilai rata-rata panjang akar $18,30 \mathrm{~cm}$.

Tebu varietas SP 80-1816 (V1) memiliki respon lebih baik dibandingkan dengan varietas PS 882 (V2) dalam hal tinggi tanaman umur 4 MST dengan tinggi tanaman rata-rata $147,26 \mathrm{~cm}$.

Interaksi antara dosis mikoriza dan varietas tebu tidak menunjukkan perbedaan yang nyata terhadap semua parameter.

Pemberian mikoriza dengan dosis 8 gram merupakan perlakuan terbaik yang diberikan pada tanaman tebu.

\section{DAFTAR PUSTAKA}

Anindita, D.C., Winarsih, S. Sebayang, H.T., \& Tyasmoro, S. Y. 2017. Pertumbuhan Bibit Satu Mata Tunas Yang Berasal Dari Nomor Mata Tunas Berbeda Pada Tanaman Tebu (Saccharum officinarum L.) Varietas Bululawang dan PS 862. Dalam J. Produksi Tanaman 3(5): 451-459. Retieved from http://protan.studentjournal.ub.ac.i d/index.php/protan/article/view/39 $\underline{9 / 410}$

Adelman, M.J, \& Morton, J.B. 1986. Infectivity Of Vesicular-Arbuscular
Mycorrhizal Fungi: Influence Of Host-Soil Diluent Combinations On MPN Estimates And Percentage Colonization. On Soil Biol. Biochem. 18(1): 77-83. Retieved from https://doi.org/10.1016/0038$\underline{\text { 0717(86)90106-9 }}$

Bailey, H. 1986. Dasar-dasar Ilmu Tanah. Palembang: Kentrucky Team UNSRI.

Basri, A. H. H. 2018. Kajian Peranan Mikoriza Dalam Bidang Pertanian. Dalam Agrica Ekstensia. 12(2): 7448. Retieved from https://polbangtanmedan.ac.id/uplo ad/upload/jurnal/Vol\%20122/11\% 20Arie\%20Mikoriza.pdf

Indika, H. 2018. Pengaruh Nomer Mata Tunas dan Pupuk Mikoriza Terhadap Pertumbuhan Tanaman tebu (Saccharum officinarum L) Metode Bud Chip. Skripsi. Retieved from https://elibrary.polije.ac.id/js/pdfjs/web/vie wer.html?file=.././../repository//A4 3140076 SKRIPSI.pdf

Ismayanti, W., Toekidjo., \& Hadisutrisno, H. 2013. Pertumbuhan Dan Tanggapan Terhadap Penyakit Karat (Puccinia kuehnii) Sembilan Klon Tebu (Saccharum officinarum L.) Yang Diinfeksi Jamur Mikoriza Arbuskular. Dalam Vegetalika 2(4). Retieved from https://doi.org/10.22146/veg.4007

Kementerian Perindustrian Republik Indonesia. 2019. "Industri Gula Digenjot".

"https://kemenperin.go.id/artikel/2 0447/Industri-Gula-Digenjot" [20 April 2020]

Mashud, N., Maliangkay, R. B., \& Nur, M. 2013. Pengaruh Pemupukan 
Terhadap Pertumbuhan Vegetatif Tanaman Aren Belum Menghasilkan. Dalam B. Palma 1(14):13-19. Retieved from http://dx.doi.org/10.21082/bp.v14n $\underline{1.2013 .13-19}$

Putra, E., Sudirman, A., \& Indrawati, W. 2016. Pengaruh Pupuk Organik Pada Pertumbuhan Vegetatif Tanaman Tebu (Saccharum officinarum L.) Varietas GMP 2 dan GMP 3. Dalam J. Agro Industri Perkebunan. 4(2): 60-68. Retieved from

http://dx.doi.org/10.25181/aip.v4i2 .44

Putri, D. A., Sudiarso., \& Islami, T. 2013. Pengaruh Komposisi Media Tanam Pada Teknik Bud Chip Tiga Varietas Tebu (Saccharum officinarum L). Dalam J. ProduksiTanaman. 1(1). Retieved from

http://protan.studentjournal.ub.ac.i d/index.php/protan/article/view/3/3

Talanca. 2010. Status Cendawan Mikoriza Vesikular-Arbuskular (MVA) Pada Tanaman. Dalam Pekan Serealia Nasional.

Talanca, A.H. 2015. Manfaat Mikoriza Vesikular-Arbuskular (MVA) Terhadap Pertumbuhan dan Pengendalian Penyakit Tanaman. Dalam Prosiding Seminar Nasional Serealia.

Wardhika, C. M., Hadisutrisno, B., \& Widada, J. 2015. Potensi Jamur Mikoriza Arbuskular Unggul dalam Peningkatan Pertumbuhan dan Kesehatan Bibit Tebu (Saccharum officinarum L.). Dalam J. Ilmu Pertanian. 18(2): 84-91.
Retieved from https://doi.org/10.22146/ipas.9088

Yulianingtyas, A. P., Sebayang, H. T., \& Tyasmoro, S. Y. 2015. Pengaruh Komposisi Media Tanam dan Ukuran Bibit Pada Pertumbuhan Pembibitan Tebu (Saccharum officinarum L.). Dalam J. Produksi Tanaman 3(5): 362-369. Retieved from http://protan.studentjournal.ub.ac.i d/index.php/protan/article/view/21 $\underline{1 / 203}$ 